Sadat, J., Pureza, R., \& Alario, F. X. (2016). Traces of An Early Learned Second Language in Discontinued Bilingualism. Language Learning, 66(S2), 210-233.

Running head: SECOND LANGUAGE TRACES IN DISCONTINUED BILINGUALISM 
1

Authors' note

3 Acknowledgements

4 This research was supported by the European Research Council (FP7/2007-2013 Grant 5 number 263575), the Brain and Language Research Institute (A*MIDEX grant ANR-

6 11-IDEX-0001-02, LABEX grant ANR-11-LABX-0036), and the Féderation de

7 Recherche 3C (Aix-Marseille Université).

8

9 Address correspondence to:

10 F.-Xavier Alario,

11 Laboratoire de Psychologie Cognitive,

12 Aix-Marseille Université-CNRS UMR 7290,

13 3, Place Victor Hugo

1413331 Marseille, France.

15 Email: francois-xavier.alario@univ-amu.fr

16 
Abstract

3

4 Can an early learnt second language influence speech production after living many

5 years in an exclusively monolingual environment? To address this issue, we

6 investigated the consequences of discontinued early bilingualism in heritage speakers

7 who moved abroad and switched language dominance from the second to the primary

8 learnt language. We used two fluency tasks to compare European Portuguese

9 monolinguals with early European Portuguese-French bilinguals who no longer use

10 French. The occurrence of cognate words in retrieval performance was used as an index

11 for the influence of the early learnt second language (French). Results showed that

12 bilinguals used more cognates than non-cognates relative to monolinguals. Also,

13 monolinguals and bilinguals produced the same number of responses in the fluency

14 tasks, and the produced words were of similar frequency. Our findings highlight that

15 early learning of a second language, even when discontinued, plays a lasting role for 16 word selection. 
1

\section{Traces of an early learnt second language in discontinued bilingualism}

Although much research has focused on the influence of a primary language on second language production (e.g., Flege, Munro, MacKay, 1996; Hermans, Bongaerts, de Bot, \& Schreuder, 1998), only few studies have looked at the linguistic remains from an early learnt second language that is not used anymore. This is usually the case for bilingual 'returnees', that is, early bilinguals who continuously used a second language during many years before moving abroad to an exclusively monolingual environment (e.g., of their first learnt language: Kanno, 2000). While it is established that linguistic knowledge of an unpracticed second language undergoes attrition (e.g., Cook, 2007; Schmid \& de Bot, 2004), it is still possible that traces of such early bilingualism endure and influence speech, even after many years of living in a different language environment. The goal of the present study is to explore the remains and influences of such an early second language experience on word production performance. To do so, we assessed the use of cognates in word retrieval performance of early bilinguals who no longer use their second language.

Cognates are translations that share meaning and are similar in form (phonologically and/or orthographically; e.g., girafa [giraffe], in European Portuguese and English); they contrast with non-cognates that only share meaning (e.g., pássaro [bird]). It has been shown that cognates are more 'resistant' to language attrition, while non-cognates tend to be lost both in language attrition and language death (see Schmid \& de Bot, 2004). More importantly for the present study, processing benefits for cognate retrieval have been shown in the two languages of a bilingual. Previous studies comparing bilingual to monolingual performance reported production benefits for cognates when compared to non-cognates (e.g., Costa, Caramazza, Sebastián-Gallés, 2000; Costa, Santesteban, \& Caño, 2005; Ivanova \& Costa, 2008; Gollan \& Acenas, 2004; for a reconsideration of 'benefits' see Sadat, Martin, Magnuson, Alario, \& Costa, in press), highlighting the special role of cognates in bilinguals. Cognate effects in word production of bilinguals suggest that the words of the two languages spread activation to their common phonological representations. The most prominent explanation regarding 
1 the origin of such a cognate effect hinges on the interactive nature of lexical processing

2 (e.g., Costa et al., 2005). Phonemes that are common across the two languages of a

3 bilingual would feed back their activation to the word level, and thus facilitate retrieval

4 of cognates compared to non-cognates (but see also Sánchez-Casas \& García-Albea,

5 2005, or Van Hell \& De Groot, 1998, for alternative explanations at the morphological

6 and conceptual level respectively). Irrespective of the precise origin of the effect, the

7 fact that cognate status is a feature of bilinguals' linguistic knowledge (but not 8 monolinguals') and that its manipulation affects performance, makes it a sensible 9 measure of other-language activation during speech production of bilinguals.

The group of bilingual speakers in the present study consisted of early bilingual heritage speakers of European Portuguese that were born and raised in France, but were, at the time of testing, living in an almost exclusively monolingual environment of their first learnt language (European Portuguese). European Portuguese has again become their dominant and now only language, as the use of their second language (French) declined drastically since they moved to their parents' country of origin. Since cognate words are more resistant to language disuse (in the non-used language), we expect them to serve as a refined index of second language influence on the used language. Thus an increased use of cognates in the used language by this type of bilinguals, compared to monolinguals, would indicate that there are still remaining traces of their early language experience that surface in their speech.

To evaluate word retrieval abilities, we implemented a standard cognitive task that is commonly used in clinical and laboratory contexts to measure word retrieval performance (e.g., Benton, 1968; Benton \& Hamsher, 1976; Lezak, 1995). In such fluency tasks, participants are asked to name a maximal number of exemplars given a single category cue, i.e., semantic (e.g., animals) or letter (e.g., words starting with the letter F) during a fixed amount of time (usually one minute; Roberts \& Le Dorze, 1997). A common assumption regarding word retrieval dynamics in this task is that the category name will activate multiple candidates and the participant must choose one name at a time, selecting from among the activated alternatives (Sandoval, Gollan, Ferreira, \& Salmon, 2010). 
Previous research has shown that this type of task can reveal differences in the linguistic behavior of mono- and bilinguals (see Table 1 for an overview of results from verbal fluency studies in bilinguals). The most common explanations for poorer performance of bilinguals as compared to monolinguals in linguistic fluency are linked to the consequences of using two languages on a daily basis. First, it is possible that bilinguals need to apply language control mechanisms during speech production to avoid interference between languages (Green, 1998), since word representations of the two languages are co-activated. This additional processing would slow down lexical access and retrieval in bilinguals compared to monolinguals, hence resulting in fewer verbal fluency responses within the allotted time. An alternative explanation relates linguistic costs to the fact that bilinguals produce speech in each of their languages overall less often than monolinguals who always speak one language only. Accordingly, a bilingual cost would result from weaker links between the semantic and phonological representations, underlying poorer word retrieval abilities in bilinguals compared to monolinguals (Gollan et al., 2008). Finally, a more recent proposal for the worse performance of bilinguals in language production relates to processing costs at postlexical stages (Hanulová et al., 2011; Sadat, Martin, Alario, \& Costa, 2012; Sadat et al., 2015). It states that processes such as phonological encoding, syllabification, and articulation may be more effortful if there are incompatibilities between the constraints of each language which in turn leads to costs in the speech of bilinguals relative to monolinguals.

In that theoretical context, we note some inconsistencies in the results of previous studies on the bilingual cost in the verbal fluency task (Table 1). For example, Rosselli et al. (2000) found that bilingual speakers differed from monolinguals on the number of exemplars produced in semantic categories, but not in letter categories. Gollan and colleagues (2002) replicated Rosselli et al.'s results with bilinguals producing fewer correct exemplars in semantic categories, but they also observed differences between speaker groups in letter categories. Although these previous studies generated mixed results (e.g., Bialystok et al., 2008b), fluency tasks still represent a common research tool used to detecting differences in linguistic processing between monolinguals and bilinguals (e.g., Blumenfeld et al., 2016). More importantly, the question of whether there is a bilingual cost in verbal fluency or not is less important for the purpose of the present study. The aim of the current study does not concern the number of words produced, but rather which type of words are produced, and whether 
1 or not they are cognates. The rate of cognate production is our proxy for testing the

2 possible remains of an early learnt second language in the speech production of

3 bilinguals who no longer use their second language, compared to monolinguals for

4 whom no cognates exist.

5 Given that the precise mechanisms and processes underlying the bilingual cost in

6 verbal performance are still unclear, it is also debated how word retrieval in semantic or

7 letter fluency tasks could be more reliably influenced by bilingualism (e.g., Sandoval et

8 al., 2010). Regarding letter fluency tasks, researchers argued that phonemic generation

9 is not a common strategy for word retrieval, and therefore should be more demanding in terms of executive control and attention than other kinds of speech elicitation tasks. Thus recent studies suggested that bilinguals would be able to compensate their linguistic deficit with an advantage in executive processing, and thus differences between the two groups of speakers should be equalized for letter fluency (e.g., Bialystok \& Craik, 2010; Friesen, Luo, Luk, \& Bialystok, 2015).

However, several previous studies also suggested that performance differences across semantic and letter categories may be driven by particular language properties. For example, Kempler, Teng, Dick, Taussig, and Davis (1998) showed that variation in verbal fluency performance across languages depended on the language of administration. In their study, Vietnamese participants produced more animal names than Spanish participants, possibly because animal names are typically monosyllabic in Vietnamese unlike multisyllabic Spanish names (but see Pekkala, Goral, Hyun, Obler, Erkinjuntti, \& Albert, 2009). Another observation also indicates that the relation between the words in the two languages impacts bilingual performance. Although some verbal fluency studies reported poorer performance of bilinguals than monolinguals, other studies showed that bilinguals produced a higher proportion of cognate words than monolinguals (Blumenfeld et al., 2016; Sandoval et al., 2010). ${ }^{1}$

Thus a possible explanation for previously reported performance differences between mono- and bilingual fluency could be that bilinguals produce more words of a certain type (e.g., cognates) in letter than in semantic categories because of the inherent linguistic properties of the tested categories (see also Michael \& Gollan, 2005). That is, bilinguals and monolinguals may not differ in the overall number of exemplars produced in letter categories because bilinguals are able to choose from a higher proportion of cognates in these categories. In contrast, in semantic categories the number of cognates may be more limited than in letter categories, and therefore 
1 bilinguals would produce less cognate exemplars simply because these words are not 2 available. Thus, we hypothesize that the number of cognates that can be produced in 3 each category as well as the restrictions set by the fluency task (in terms of time or type 4 of category) is an important factor to be controlled for in this context.

An additional word property that previous studies suggested to explain the 6 poorer bilingual performance in fluency tasks relates to the actual frequency values of the generated responses (Gollan, Montoya, Cera, \& Sandoval, 2008). Although Rosselli et al. (2000) showed that monolinguals outperformed bilinguals on semantic categories, some categories still allowed for a better performance in one of the bilingual's languages depending on the frequency of the exemplars. Thus, if bilingual participants were more used to naming animals in language $\mathrm{A}$ than $\mathrm{B}$, performance regarding animal retrieval in language A was better than in language B. It seems reasonable that bilinguals retrieve and name words that they usually produce in one language faster than words that they are not used to producing in that language (Gollan et al., 2008). For this reason, we will also assess and compare the frequency values of the responses generated by mono- and bilinguals in the two experiments of the current study.

In sum, the aim of the present study was to test for the influence of an early learnt second language in bilinguals' word retrieval by assessing cognate production. We will do so by using a fluency task, which has previously been shown to reveal bilingualism effects in active bilinguals, while controlling for important distributional properties of the words.

\section{Experiment 1: Typed fluency task}

To control for the distributional properties of the candidate words, we estimated a priori the maximum number of cognates that could be generated in the respective semantic categories. This allowed controlling the proportion of cognate vs. non-cognate candidates per category. In Experiment 1, a standard fluency task was administered that contained semantic and letter categories with an increased response time window of five minutes. The increased response time will allow for a more exhaustive assessment of the word retrieval performance of mono- and bilinguals over time. Such extended response windows are common in studies that thoroughly investigate the dynamics underlying semantic retrieval of words from human memory (e.g., Hills, Jones, \& Todd, 2012). In addition, responses were typed on a keyboard rather than spoken to ease coding and post-processing. 
Method

\section{Participants}

The bilingual group consisted of 24 European Portuguese-French bilinguals, born in France and descendents of emigrant European Portuguese parents (17 women, 7 men). They all filled out a shortened online version of the Language History Questionnaire (Li, Sepanski, \& Zhao, 2006) to provide language usage characteristics (see Table 2 for a summary). All bilinguals stated that European Portuguese was their native language (as well as French in some cases), and that they acquired both languages starting from birth. They indicated that French was their dominant language while living in France, although nowadays European Portuguese has become their dominant language. These participants were balanced bilinguals in their early childhood who went back to Portugal during their youth, and at present live in an almost exclusive monolingual environment. Participants consistently reported that while living in France, they spent most of their time in French monolingual contexts except at home. When they moved back to Portugal, there was a complete language dominance switch to European Portuguese. Bilinguals confirmed that French is used only in few particular situations (e.g., talking on the phone with family and friends; watching French movies). For the control group, 24 European Portuguese native monolingual speakers were tested (17 women, 7 men; $M=23.58$ years old, $S D=4.36$ ). Monolinguals had a medium level of English from formal high school education (similar to bilinguals), but no knowledge of French.

\section{Materials}

$<$ Insert Table 2 about here $>$

The typed fluency task in Experiment 1 consisted of three semantic categories and three letter categories. In order to estimate the number of European PortugueseFrench cognate words that could be produced across semantic categories, we used a French database (Basety, Léger, Boumlak, \& Tijus, 2008) from which nine out of twenty-one categories were translated to European Portuguese, excluding compound words (no similar database was available for European Portuguese; however; given a certain degree of cultural and environmental similarities between France and Portugal, we reasoned that mention in the French database was a good approximation of mention 
1 in a putative Portuguese database). For each exemplar in Basety, the appropriate

2 translation in European Portuguese was taken from 'The Free Dictionary'

3 (http://www.thefreedictionary.com/) and 'Infopedia' (http://www.infopedia.pt/).

4 Phonetic transcription was transferred from Lexique 3.71 (New, Pallier, Ferrand, \&

5 Matos, 2001) and revised by a phonetic expert. A word was considered to be a cognate

6 if it had less than 0.25 Levenshtein's distance values, i.e., if it needed less than three

7 substitutions to edit one string into its equivalent translation (considering insertions and

8 deletions, e.g., Dijkstra, Miwa, Brummelhuis, Sappelli, \& Baayen, 2010).

9 The proportions of cognate (vs. non-cognate) words obtained for each semantic category were: animals $-32 \%$; fruits $-35 \%$; musical instruments $-55 \%$; vegetables $26 \%$; furniture $-37 \%$; tools $-19 \%$; professions $-15 \%$; vehicles $-38 \%$; and clothing $41 \%$. The chosen semantic categories were 'fruits', 'furniture' and 'clothing', because they had a good mix of cognates and non-cognates as well as a good pool of exemplars possible to name in the time range of the task. Given that there is not much (if any) literature for the letter fluency task in European Portuguese, we decided to choose three letters that were not to be used in Experiment 2 (see below) to avoid perseverations. Portuguese lexical frequency values for the responses were extracted from the program Procura-PALavras (P-PAL; Soares et al., 2014) and are reported in log frequency per million words.

\section{Procedure}

Participants were asked to type as many exemplars as possible for the semantic categories 'fruits', 'furniture' and 'clothing', and the letter categories ' $\mathrm{D}$ ', 'O', and ' $\mathrm{V}$ '. In most fluency tasks, participants are given 60 seconds to give as many responses as possible. However, in the present study participants were given five minutes for each semantic or letter category in order to increase the time period of possible answers for potential differences between groups to unfold over time, and to understand if the pattern of responses was maintained during a more extended time period. The presentation of the categories was alternated between semantic and letter fluency according to a Latin square design (12 lists - two participants per list). The software DMDX was used for the presentation of the categories and data recording (Forster \& Forster, 2003).

To ease response coding, participants typed their responses on a standard computer keyboard rather than speaking out loud. This procedure is expected to lead to 
1 slightly slower responses than with oral production. However, given the extended 2 response window, this modification was not crucial to our purposes, and typed 3 responses afforded considerably simpler post-processing and coding than spoken 4 responses.

5

\section{Results}

In the semantic categories, exemplars belonging to a super-ordinate category (e.g., clothes) were considered correct answers except if subcategory exemplars were presented as well (e.g., jacket, skirt, etc.). If this happened, each subcategory exemplar was considered correct and not the super-ordinate exemplar. Responses were coded by the experimenter and considered errors when they were perseverations (repetition of the same word), intrusions (words that did not belong to the category), and non-words (e.g., incorrectly typed words); these were excluded from the analyses and not treated any further. Moreover, all proper name responses (mostly cognates by nature) were excluded $(5.35 \%)$ since the production of this type of words does not need to be driven by traces of the second language, and their inclusion would artificially increase the count of cognates. Each exemplar was considered to be a cognate or non-cognate according to the criteria explained in the Materials section.

\section{$<$ Insert Figure 1 about here $>$}

There was an average of 79 responses across categories (letter: $M=80, S D=21$; semantic: $M=77, S D=17)$, with a maximum of 126 and a minimum of 42 answers. Overall, monolinguals and bilinguals produced a similar number of responses in the time given (see Figure 1 for an overview; monolinguals: 3761 responses; bilinguals: 3779 responses; $\left.\chi^{2}(1, \mathrm{~N}=7540)=0.04, \mathrm{p}=0.84\right)$.

Responses that were cognates (monolinguals: 1733 trials; bilinguals: 1844 trials) were contrasted with non-cognate responses (monolinguals: 2028 trials; bilinguals: 1935 trials) to estimate whether the probability of producing a cognate response was modulated by the experimental factors. A logistic mixed-effects model included predictors for speaker group (bilinguals vs. monolinguals), task (semantic vs. letter category), order (i.e., the order of production of each exemplar during the time available to respond), and by-participant and by-category random intercepts (i.e., letter category 'D', 'V', 'O', and semantic category 'fruits', 'clothing', 'furniture'). We included all 
1 predictors, tested for possible interactions, and retained only those contributing significantly to the model using a backward elimination procedure. ${ }^{2}$

The probability of producing a cognate was significantly higher for bilinguals than monolinguals (see Figure 2). The effect of task was significant, such that the probability of producing a cognate was higher in the letter than semantic category task. The overall effect of order was also significant, such that the probability of producing a cognate increased with increasing retrieval order. The interactions between speaker group and the other predictors were not significant. Statistical values for the significant predictors of cognate production probability are reported in Table 3.

$<$ Insert Table 3 about here $>$

$<$ Insert Figure 2 about here $>$

It is possible that the individual language usage characteristics of the bilinguals (taken from the Language History Questionnaire; see Table 2) could have influenced the present cognate effect. If these ratings would be predictive of the usage of cognate words, one could argue that cognate retrieval should vary depending on the individual amount of French usage. For example, participants who at present do not have any French exposure at all could show a smaller cognate effect in the present task than participants who still have little exposure. To test this hypothesis, we added these variables as predictors in the previous logistic mixed-effects model. In particular, we looked at the effect of number of hours and percentage of time speaking in French and in European Portuguese, the participants' age, the years spent in France and in Portugal, and the context of learning their second language French (at home, at school, or both). None of these variables were significant in predicting cognate production probability. Such absence of effect could well be due to our questionnaires not being detailed enough to obtain fine-grained measures for these variables. It remains to be established whether and how such variables might influence variability of the cognate effect at an individual level.

Finally, we also looked at the frequency values of the produced words to examine whether mono- and bilinguals differed in the types of words they produced. We classified all responses into three categories: (1) words that were produced by both mono- and bilinguals, (2) words that were produced by bilinguals only, and (3) words 
1 that were produced by monolinguals only. Mean frequency values of the produced

2 words were virtually the same between the subset of words unique to monolinguals ( $M$

$3=0.62, S D=0.17)$ and the one unique to bilinguals $(M=0.65, S D=0.12 ; \mathrm{t}[46]=0.65$,

$4 \mathrm{p}=0.52)$. Across all participants, the produced cognates $(M=0.79, S D=0.67)$ were of

5 lower mean frequency than the non-cognates $(M=0.83, S D=0.73 ; \mathrm{t}[94]=-2.36, \mathrm{p}=$ $6 \quad 0.02)$.

7

8

\section{Experiment 2: Mixed task}

In Experiment 2, we used a constrained fluency task (mixed task) in which participants were asked to give a single response that belonged to a particular semantic category, and started with a specific first letter (e.g., ANIMALS: B). These category pairs were selected considering combinations that could produce both cognate and noncognate exemplars to an equal extent, using the available semantic database. Previous studies showed that bilinguals usually produced a higher proportion of cognates in letter categories than in semantic categories (Blumenfeld et al., 2016; Sandoval et al., 2010). In a mixed task like Experiment 2 that is more constrained than the standard fluency task, we predict that, given the equal probability of producing a cognate and a noncognate, bilinguals would be more likely to select a cognate word from among all possible candidates.

\section{Method}

Participants

Participants in Experiment 2 were the same as in Experiment 1, with 24 European Portuguese-French bilinguals and 24 European Portuguese native monolinguals.

\section{Materials}

The mixed task consisted of individual trials for a semantic category together with a first letter (e.g., 'ANIMAL: B'). For the nine semantic category translated to European Portuguese, we looked at the number of exemplars that could be elicited for each letter. Given that age of acquisition is one of the most influential predictors of lexical availability (Hernandez-Muñoz, Izura, \& Ellis, 2006), the potential responses to letter category pairs were controlled for frequency and age of acquisition in European Portuguese (i.e.,very typical exemplars were excluded, like 'ANIMAL: C' - cão [dog]; 
1 Marques, Fonseca, Morais, \& Pinto, 2007; Soares et al., 2010). Each combination of a

2 semantic category and letter had roughly similar probabilities of generating cognates or

3 non-cognates (e.g., for the semantic category 'animals' starting with the letter ' $A$ ', there

4 were eight possible cognate candidates and eight possible non-cognate candidates). A

5 total of thirty trials were created with six semantic categories and a maximum of seven

6 and a minimum of three letters per category. The selected categories were 'animals'

7 (32\% of cognates on average), 'musical instruments' (55\% of cognates on average),

8 'vegetables' (26\% of cognates on average), 'tools' (19\% of cognates on average),

9 'professions' (15\% of cognates on average), and 'vehicles' (38\% of cognates on average). In Table 4, all the retained combinations of category and letter in the mixed task are presented. Frequency values for the responses were extracted from the program Procura-PALavras (P-PAL; Soares et al., 2014) and are reported in log frequency per million words.

$<$ Insert Table 4 about here>

\section{Procedure}

Each pair (category and letter) was presented for 30 seconds or until the participant finished typing their answer. The Mix program (van Casteren \& Davis, 2006) was used to randomizing the order of presentation, with a minimal distance of two between the same category or the same letter, creating a different order for each participant (both bilinguals and monolinguals). The software DMDX was used for the presentation of the categories and data recording (Forster \& Forster, 2003).

Participants were asked to type the first exemplar that came to their minds matching the required semantic and letter category. They were asked to answer as fast as possible while trying to avoid mistakes. For all participants, Experiment 2 was administered after a short break following Experiment 1.

\section{Results}

As in Experiment 1, we used a logistic mixed-effects model to explore the probability of cognate production in the mixed task. Responses that were cognates (monolinguals: 277 trials; bilinguals: 302 trials) were contrasted with non-cognate responses (monolinguals: 274 trials; bilinguals: 245 trials) to accurately predict the probability of producing a cognate response. The model included the predictors speaker 
1 group (bilinguals vs. monolinguals), trial order (i.e., the order of occurrence of a

2 specific category), the interaction between these two, and by-participant and by-

3 category random intercepts (e.g., animal starting with letter ' $m$ ').

4

5

6

Results showed that the probability of producing a cognate was significantly higher for bilinguals than monolinguals $(\beta=-0.77, \mathrm{SE}=0.27, \mathrm{z}[1092]=-2.87, \mathrm{p}=$ 0.004; see Figure 3). The effect of trial order was not significant. However, the interaction between speaker group and trial order was significant, such that with increasing trial order the probability of producing a cognate was lower for bilinguals than for monolinguals $(\beta=0.04, \mathrm{SE}=0.02, \mathrm{z}[1092]=2.17, \mathrm{p}=0.030)$.

\section{$<$ Insert Figure 3 about here $>$}

Importantly, the effects reported for Experiment 2 confirm the pattern of results obtained in Experiment 1 and show more precisely that early bilinguals retrieve more cognates than non-cognates during word production than monolinguals. As in Experiment 1, the bilinguals' language history characteristics were not significant in predicting cognate production probability. Finally, we also looked at the frequency values of the words produced to examine whether mono- and bilinguals differed in the types of words they produced. We classified all responses into three categories: (1) words that were produced by both mono- and bilinguals, (2) words that were produced by bilinguals only, and (3) words that were produced by monolinguals only. Mean frequency values of the produced words were similar between the subset of words unique to monolinguals $(M=0.53, S D=0.22)$ and the one unique to bilinguals $(M=$ $0.49, S D=0.28 ; \mathrm{t}[45]=-0.58, \mathrm{p}=0.57)$. Across all participants, the produced cognates $(M=0.61, S D=0.40)$ were of similar mean frequency than the non-cognates $(M=0.59$, $S D=0.43 ; \mathrm{t}[94]=1.06, \mathrm{p}=0.29)$.

In the present study, we explored the influence of an early learnt second language on word retrieval in bilinguals who no longer use their second language. We used two modified fluency tasks and compared bilinguals' (typed) word production to that of monolinguals by investigating the use of cognate words. In Experiment 1, participants were asked to respond to three semantic and three letter categories. Two 
methodological changes were adopted to ease the interpretation of fluency performance: the response time window of the task was increased, leaving participants five minutes instead of the standard time of 60 seconds to consider retrieval performance more exhaustively. We also conducted an a priori estimation of the proportion of cognate words in each of the semantic categories, thus controlling for a factor that could have been responsible for previously reported poorer performance of bilinguals. In Experiment 2, a restricted fluency task, participants were asked to retrieve a single exemplar of a semantic category starting with a given letter. In this task again, responses in each category pair could generate either a cognate or a non-cognate response at equal rates.

In the extended fluency task (Experiment 1), monolinguals and bilinguals produced the same number of responses during the time given. Contrary to previous studies (e.g., Gollan et al., 2002; Sandoval et al., 2010), bilinguals did not present a retrieval cost in the fluency task compared to monolinguals. Moreover, in the current study there was no performance difference across semantic and letter categories for these two groups of speakers (e.g., Rosseli et al., 2002; see Table 1 for a summary of previous evidence). In addition, the present data does not suggest any differences between mono- and bilinguals in terms of frequency values for the retrieved words. Previous studies suspected that bilinguals would show a bias towards using higher frequency words when asked to generate responses in their first and second language (Gollan et al., 2002). The fact that we did not observe any differences in the frequency values of the generated words may be due to the fact that our bilingual participants were 'virtually' monolingual, and that they were using their first language. The bilinguals of our study had been living in an exclusively monolingual context for many years and their use of a second language had been drastically reduced. It seems likely that after so many years of no longer using a second language, the bilinguals' word use would resemble those of a monolingual in terms of frequency measures. Moreover, the explanation of using words of lower frequency in the speech production of bilinguals seems difficult to transfer to verbal fluency performance in a bilingual's first language.

However, the key difference we observed between mono- and bilinguals' performance was a higher number of cognates produced by bilinguals in both letter and semantic categories. The fact that we found a larger number of cognate words used in the present type of bilinguals shows that early language learning impacts current word 
1 selection, even though the early learnt language has been discontinued for many years

2 and speakers had been living in an exclusively monolingual language environment.

The present results also showed that the probability of producing a cognate was overall higher in the letter than in the semantic categories. One possible explanation for this observation is that letter categories are overall larger than semantic categories 6 thereby allowing for a larger number of selectable cognate words (Blumenfeld et al., 2016; Michael \& Gollan, 2005). In previous studies on verbal fluency with bilinguals there was no information on the distribution of available cognates per fluency categories. Therefore, it is possible that the differences between letter and semantic categories may have been caused by the number of cognates that the participants could (or could not) produce. The present study made an important step forward in tackling this problem by taking into account an a priori estimation of cognate and non-cognate distribution per category. than that used in most previous studies (five vs. one minute). To compare our results with previous fluency studies, we applied the same analysis as above to a subset of the fluency data of Experiment 1 comprising the first minute only (see also Sandoval et al., 2010 for investigating different time bins during the first minute of a fluency trial). For this subset of the first minute, the difference in the number of responses between monolinguals and bilinguals was marginally significant, with monolinguals producing slightly more responses than bilinguals (monolinguals: 1553 responses [semantic: 881; letter: 672]; bilinguals: 1449 responses [semantic: 805; letter: 644]; $\chi^{2}(1, \mathrm{~N}=3002)$ $=3.60, \mathrm{p}=0.06$ ). However, the difference between mono- and bilinguals in the probability of producing cognates was not significant. All other effects were the same as in the main analysis presented above (e.g., a higher probability of producing a cognate in the letter than semantic category task for both speaker groups). This means that when only considering the first minute our results are in line with some of the previous verbal fluency studies reporting slightly reduced word retrieval for bilinguals than monolinguals (see Table 1). Our results show, however, that when participants are given enough time, differences in the number of retrieved responses across speakers are not maintained, and differences in the type of responses (i.e., cognates) become obvious. It is difficult to hypothesize how word retrieval dynamics depend on such temporal constraints and how this would apply to explanations of a bilingual cost (e.g., see Sandoval et al., 2010), especially in this particular population of early bilinguals who no 
1 longer use their second language. However, irrespective of these different theories, our 2 results show that in bilinguals who have not used a second language for an extended 3 time, the occurrence of cognate words in verbal fluency tasks is sensitive to the 4 extension of the response time window. Future studies on fluency performance of 5 bilinguals should consider using the methodological modifications we adopted to 6 broaden the sensitivity of the fluency task.

Importantly, bilinguals also produced more cognate words than monolinguals in the mixed experiment (Experiment 2) in which participants were required to respond with a single exemplar only. The mixed task was more controlled compared to standard fluency tasks in terms of possible response candidates. Thus the results of Experiment 2 replicate and extend the pattern of increased cognate production for bilinguals obtained in Experiment 1.

It seems reasonable to assume that the current results depend on the many factors defining different bilingual populations. For example, recent studies testing mono- and bilingual speakers on verbal fluency tasks showed that proficiency is a major determinant for cognate use in bilinguals (e.g., Bluemenfeld et al., 2016; Kormi-Nouri et al., 2012). However, explanations in the present study for why bilinguals would use more cognates in speech production than monolinguals evolve less around proficiency or early age of acquisition, since all bilinguals had acquired their second language from very early on and with a high degree of proficiency. Instead, unlike previous studies, the present study allows distinguishing effects of high proficiency and early age of acquisition from effects of high frequency of use. Thus, our results point to the lasting impact of second language phonology on first language production, even in cases when usage is drastically reduced. In this context it is also important to mention another factor that seems to be influential for cognate production in bilinguals. The amount of cognate use may depend on the phonological similarity of the bilingual's two languages, meaning that for more similar languages, bilinguals would be more likely to engage in cognate production. The present study tested bilinguals of two Romance languages, European Portuguese and French. To get an idea of the role of language similarity for cognate production, we identified the percentage of unique responses in our two experiments, and assessed the percentage of cognates and non-cognates between, on the one hand, European Portuguese and French, and on the other hand, European Portuguese and a more distant language such as English. The proportion of cognate responses for European Portuguese and French was similar in Experiment 1 (57\%) and 
$12(56 \%)$. In comparison, the proportion of cognate responses between European

2 Portuguese and English was lower (Experiment 1: 30\%; Experiment 2: 38\%). Thus it

3 may be possible that the closer linguistic similarity of European Portuguese and French

4 aided detecting the use of cognates in this particular type of bilinguals. Future studies

5 need to further determine the role of language similarity for cognate production in

6 bilinguals.

7 In a verbal fluency task which resembles an associative search tasks, inter-

8 language form similarity could help in cueing the phonological encoding of target

9 words that fit the selection criteria (see e.g., Sadat, Martin, Costa, \& Alario, 2014, for a review on how phonological similarity influences speech production in different contexts). When compared to monolingual performance, the absence of inter-language form similarity will thus lead to a cost in bilingual lexical access. This may for example induce a higher number of unresolved tip-of-the-tongue states in the case of noncognates for bilinguals compared to monolinguals, as well as a bilingual cost in naming performance in the case of non-cognates (Sadat et al., 2015). Overall, the current results highlight that phonological similarity across languages plays an important and lasting role for bilingual lexical access, even after many years of living in another language environment.

It is also worth mentioning that the population of bilinguals in the current study contrasts with participants of previous studies that explored the long-term consequences of language learning during an early critical period (e.g., Pallier et al., 2003; Ventureyra, Pallier, \& Yoo, 2004). In that research, participants were early adoptees for which their first learnt language had undergone complete attrition (but see Pierce, Klein, Chen, Delcenserie, \& Genesee, 2014). For example, Pallier and colleagues tested if there would be any unconscious influences from an early leant language on their participants' speech perception or in their neural language circuitry, but did not observe any remaining language sensitivity. Thus it is clear that an early exposure of a second language is simply not enough to ensure remaining elements in later speech production. In contrast, the bilinguals of the current study had been raised and lived for many years as highly proficient bilinguals before entering into an exclusive monolingual environment.

In sum, the present study establishes the long lasting impact of previously having learnt and mastered another language on the speech production of early bilinguals who no longer use their second language. Altogether, a bilingual's word 
1 retrieval in their first language is influenced by an early learnt second language, even 2 after many years of disuse.

3

4 
2 1. The difference in cognate production between monolinguals and bilinguals in 3 Sandoval et al. (2010) was only apparent in the proportions, not in the absolute 4 number of produced cognates (due to unequal numbers of total responses between 5 monolinguals and bilinguals).

6 2. Including maximal individual by-random slopes into the logistic model did not 7 improve the model's fit and thus we retained the model with simple by-participant $8 \quad$ and by-item intercept random slopes. 
References

3 Benton, A.L. (1968). Differential behavioral effects of frontal lobe disease. Neuropsychologia, 6, 53-60. doi:10.1016/0028-3932(68)90038-9

Benton, A.L., Hamsher, K. (1976): Multilingual Aphasia Examination. Iowa City, Iowa: AJA Associates.

Bialystok, E., \& Craik, F. I. (2010). Cognitive and linguistic processing in the bilingual mind. Current Directions in Psychological Science, 19 (1), 19-23. doi:10.1177/0963721409358571

Bialystok, E., Craik, F. I., \& Luk, G. (2008b). Lexical access in bilinguals: Effects of vocabulary size and executive control. Journal of Neurolinguistics, 21(6), 522538. doi:10.1016/j.jneuroling.2007.07.001

Bialystok, E., Craik, F.I., \& Luk, G. (2008a). Cognitive control and lexical access in younger and older bilinguals. Journal of Experimental Psychology: Learning, memory, and cognition, 34(4), 859-873. doi:10.1037/0278-7393.34.4.859

Blumenfeld, H. K., Bobb, S. C., \& Marian, V. (2016). The role of language proficiency, cognate status and word frequency in the assessment of Spanish-English bilinguals' verbal fluency. International Journal of Speech-Language Pathology, 18(2), 1-12. doi:10.3109/17549507.2015.1081288

Bolla, K. I., Gray, S., Resnick, S. M., Galante, R., \& Kawas, C. (1998). Category and letter fluency in highly educated older adults. The Clinical Neuropsychologist, 12(3), 330-338. doi:10.1076/clin.12.3.330.1986

Capitani, E., Laiacona, M., \& Barbarotto, R. (1999). Gender affects word retrieval of certain categories in semantic fluency tasks. Cortex, 35(2), 273-278. doi:10.1016/S0010-9452(08)70800-1

Cook, V. (2007). The nature of the L2 user. EUROSLA Yearbook, 7(1), 205-220.

Costa, A., Caramazza, A., \& Sebastian-Galles, N. (2000). The cognate facilitation effect: Implications for models of lexical access. Journal of Experimental Psychology: Learning, Memory, and Cognition, 26(5), 1283-1296. doi:10.1037//0278-7393.26.5.1283

Costa, A., Santesteban, M., \& Caño, A. (2005). On the facilitatory effects of cognate words in bilingual speech production. Brain and Language, 94, 94-103. doi:doi:10.1016/j.bandl.2004.12.002 
1 Crossley, M., D'Arcy, C., \& Rawson, N. S. (1997). Letter and category fluency in community-dwelling Canadian seniors: A comparison of normal participants to those with dementia of the Alzheimer or vascular type. Journal of Clinical and Experimental Neuropsychology, 19(1), 52-62. doi:10.1080/01688639708403836

Dijkstra, T., Miwa, K., Brummelhuis, B., Sappelli, M., \& Baayen, H. (2010). How cross-language similarity and task demands affect cognate recognition. Journal of Memory and Language, 62(3), 284-301. doi:10.1016/j.jml.2009.12.003

Flege, J. E., Munro, M. J., \& MacKay, I. R. (1996). Factors affecting the production of word-initial consonants in a second language. In R. Bayley \& D.R. Preston (Eds) Second language acquisition and linguistic variation (vol. 10, pp 47-73), John Benjamins.

Forster, K. I., \& Forster, J. C. (2003). DMDX: A Windows display program with millisecond accuracy. Behavior Research Methods, Instruments, \& Computers, 35(1), 116-124. doi:10.3758/BF03195503

Friesen, D. C., Luo, L., Luk, G., \& Bialystok, E. (2015). Proficiency and control in verbal fluency performance across the lifespan for monolinguals and bilinguals. Language, Cognition and Neuroscience, 30(3), 238-250. doi:10.1080/23273798.2014.918630

Gollan, T. H., \& Acenas, L. R. (2004). What is a TOT? Cognate and translation effects on tip-of-the-tongue states in Spanish-English and Tagalog-English bilinguals. Journal of Experimental Psychology: Learning, Memory, and Cognition, 30(1), 246-269. doi:10.1037/0278-7393.30.1.246

Gollan, T. H., Montoya, R. I. \& Werner, G. A. (2002). Semantic and letter fluency in Spanish-English bilinguals. Neuropsychology, 16, 562-576. doi:10.1037//08944105.16.4.562

Gollan, T. H., Montoya, R. I., Cera, C. M. \& Sandoval, T. C. (2008). More use almost always means a smaller frequency effect: Aging, bilingualism, and the weaker links hypothesis. Journal of Memory and Language, 58, 787-814. doi:10.1016/j.jml.2007.07.001

Gollan, T. H., Montoya, R., Fennema-Notestine, C., \& Morris, S. (2005). Bilingualism affects picture naming but not picture classification. Memory and Cognition, 33(7), 1220-1234. doi: 10.3758/BF03193224

Hermans, D., Bongaerts, T., De Bot, K., \& Schreuder, R. (1998). Producing words in a foreign language: Can speakers prevent interference from their first language? 
Bilingualism: Language and Cognition, 1(3), 213-229. doi: 10.1017/S1366728998000364

Hills, T. T., Jones, M. N., \& Todd, P. M. (2012). Optimal foraging in semantic memory. Psychological Review, 119(2), 431-440. doi: 10.1037/a0027373

Ivanova, I., \& Costa, A. (2008). Does bilingualism hamper lexical access in speech production? Acta Psychologica, 127, 277-288. doi: 10.1016/j.actpsy.2007.06.003

Kanno, Y. (2000). Bilingualism and identity: The stories of Japanese returnees. International Journal of Bilingual Education and Bilingualism, 3(1), 1-18. doi: $10.1080 / 13670050008667697$

Kempler, D., Teng, E.L., Dick, M., Taussig, M., Davis, D.S. (1998). The effects of age, education, and ethnicity on verbal fluency. Journal of the International Neuropsychological Society, 4, 531-538. doi:N/A

Kormi-Nouri, R., Moradi, A. R., Moradi, S., Akbari-Zardkhaneh, S., \& Zahedian, H. (2012). The effect of bilingualism on letter and category fluency tasks in primary school children: Advantage or disadvantage? Bilingualism: Language and Cognition, 15(2), 351-364. doi: 10.1017/S1366728910000192

Kozora, E., \& Cullum, C. M. (1995). Generative naming in normal aging: Total output and qualitative changes using phonemic and semantic constraints. The Clinical Neuropsychologist, 9(4), 313-320. doi:10.1080/13854049508400495

Léger, L., Boumlak, H., \& Tijus, C. (2008). BASETY: Extension et typicalité des exemplaires pour 21 catégories d'objets. Canadian Journal of Experimental Psychology/Revue canadienne de psychologie expérimentale, 62(4), 223-232. doi: $10.1037 / \mathrm{a} 0012885$

Lezak, M. D. (1995). Neuropsychological assessment (3rd ed.). New York: Oxford University Press.

Li, P., Sepanski, S., \& Zhao, X. (2006). Language history questionnaire: A web-based interface for bilingual research. Behavior Research Methods, 38(2), 202-210. doi: 10.3758/BF03192770

Luo, L., Luk, G., \& Bialystok, E. (2010). Effect of language proficiency and executive control on verbal fluency performance in bilinguals. Cognition, 114(1), 29-41. doi:10.1016/j.cognition.2009.08.014

Marques, J. F., Fonseca, F. L., Morais, S., \& Pinto, I. A. (2007). Estimated age of acquisition norms for 834 Portuguese nouns and their relation with other 
psycholinguistic variables. Behavior Research Methods, 39(3), 439-444. doi: 10.3758/BF03193013

Michael, E.B., \& Gollan, T.H. (2005). Being and becoming bilingual: Individual differences and consequences for language production. In J.F. Kroll \& A.M.B. de Groot (Eds.) Handbook of bilingualism: Psycholinguistic Approaches (pp. 389-407). New York: Oxford University Press.

Monsch, A. U., Bondi, M. W., Butters, N., Salmon, D. P., Katzman, R., \& Thal, L. J. (1992). Comparisons of verbal fluency tasks in the detection of dementia of the Alzheimer type.Archives of Neurology, 49(12), 1253-1258. doi: 10.1001/archneur.1992.00530360051017

New, B., Pallier, C., Ferrand, L., \& Matos, R. (2001). Une base de données lexicales du français contemporain sur internet: LEXIQUETM / A lexical database for contemporary French: LEXIQUETM. L'Année Psychologique, 101(3), 447-462. doi: 10.3406/psy.2001.1341

Pallier, C., Dehaene, S., Poline, J. B., LeBihan, D., Argenti, A. M., Dupoux, E., \& Mehler, J. (2003). Brain imaging of language plasticity in adopted adults: Can a second language replace the first? Cerebral Cortex, 13(2), 155-161. doi: $10.1093 /$ cercor/13.2.155

Pekkala, S., Goral, M., Hyun, J., Obler, L. K., Erkinjuntti, T., \& Albert, M. L. (2009). Semantic verbal fluency in two contrasting languages. Clinical Linguistics \& Phonetics, 23(6), 431-445. doi: 10.1080/02699200902839800

Pierce, L. J., Klein, D., Chen, J. K., Delcenserie, A., \& Genesee, F. (2014). Mapping the unconscious maintenance of a lost first language. Proceedings of the National Academy of Sciences, 111(48), 17314-17319. doi: 10.1073/pnas.1409411111

Portocarrero, J. S., Burright, R. G. \& Donovick, P. J. (2007). Vocabulary and verbal fluency of bilingual and monolingual college students. Archives of Clinical Neuropsychology, 22, 415-422. doi: 10.1016/j.acn.2007.01.015

Roberts, P. M., \& Le Dorze, G. (1997). Semantic organization, strategy use, and productivity in bilingual semantic verbal fluency. Brain and Language, 59, 412449. doi:10.1006/brln.1997.1753

Rosselli, M., Ardila, A., Salvatierra, J., Marquez, M., Matos, L., \& Weekes, V. A. (2002). A cross-linguistic comparison of verbal fluency tests. International Journal of Neuroscience, 112, 759-776. doi: 10.1080/00207450290025752 
1 Rosselli, M., Ardilla, A., Arujo, K., Weekes, V. A., Caracciolo, V., Padilla, M. \& Ostrosky-Solis, F. (2000). Verbal fluency and repetition skills in healthy older Spanish English bilinguals. Applied Neuropsychology, 7, 17-24. doi: 10.1207/S15324826AN0701_3

Sadat, J., Martin, C., Alario, F.-X., \& Costa, A. (2012). Characterizing the Bilingual Disadvantage in Noun Phrase Production. Journal of Psycholinguistic Research, 41 (3), 159-179. doi:10.1007/s10936-011-9183-1.

Sadat, J., Martin, C., Alario, F.-X., \& Costa, A. (in press). Breaking down the bilingual cost in speech production. Cognitive Science. doi : 10.1111/cogs.12315

Sadat, J., Martin, C., Costa, A., \& Alario, F.-X. (2014). Reconciling Phonological Neighborhood Effects in Speech Production through Single Trial Analysis. Cognitive Psychology, 68, 33-58. doi:10.1016/j.cogpsych.2013.10.001

Sandoval, T. C., Gollan, T. H., Ferreira, V. S., \& Salmon, D. P. (2010). What causes the bilingual disadvantage in verbal fluency? The dual-task analogy. Bilingualism: Language and Cognition, 13(2), 231-252. doi: 10.1017/S1366728909990514

Schmid, M. S., \& De Bot, K. (2004). Language attrition. In A. Davies \& C. Elder (Eds.), The Handbook of Applied Linguistics (pp. 210-234). Oxford: Blackwell Publishing.

Soares, A. P., Comesaña, M., Iriarte, A., Almeida, J. J., Simões, A., Costa, A., . . . Machado, J. (2010). P-PAL: Uma base lexical com índices psicolinguísticos do Português Europeu [P-PAL: A European Portuguese lexical database]. Linguamática, 2, 67-72. doi:N/A

Taler, V., Johns, B. T., Young, K., Sheppard, C., \& Jones, M. N. (2013). A computational analysis of semantic structure in bilingual verbal fluency performance. Journal of Memory and Language, 69, 607-618. doi: doi:10.1016/j.jml.2013.08.004

Tombaugh, T. N., Kozak, J., \& Rees, L. (1999). Normative data stratified by age and education for two measures of verbal fluency: FAS and animal naming. Archives of Clinical Neuropsychology, 14(2), 167-177. doi:10.1016/S08876177(97)00095-4

Tomer, R., \& Levin, B. E. (1993). Differential effects of aging on two verbal fluency tasks. Perceptual and Motor Skills, 76(2), 465-466. doi: 10.2466/pms.1993.76.2.465 
1 Van Casteren, M., \& Davis, M. H. (2006). Mix, a program for

2

3

4 Vega-Mendoza, M., West, H., Sorace, A., \& Bak, T. H. (2015). The impact of late, non5

6

7

8

9

10 pseudorandomization. Behavior Research Methods, 38(4), 584-589. doi: 10.3758/BF03193889 balanced bilingualism on cognitive performance. Cognition, 137, 40-46. doi:10.1016/j.cognition.2014.12.008

Ventureyra, V. A., Pallier, C., \& Yoo, H. Y. (2004). The loss of first language phonetic perception in adopted Koreans. Journal of Neurolinguistics, 17(1), 79-91. doi:10.1016/S0911-6044(03)00053-8 
1 Table 1: Overview of verbal fluency studies comparing the number of exemplars

2 produced by monolingual and bilingual speakers (children, younger or older adults)

\begin{tabular}{|c|c|c|}
\hline Task & Study & Observation \\
\hline \multicolumn{3}{|c|}{ Semantic fluency } \\
\hline & Bialystok et al. (2008b; Study 1 and 2) & monolinguals $=$ bilinguals \\
\hline & Blumenfeld et al. (2016) & monolinguals $=$ bilinguals \\
\hline & Current study & monolinguals $=$ bilinguals \\
\hline & Friesen et al. (2015) & monolinguals $=$ bilinguals \\
\hline & Luo et al. (2010) & monolinguals $=$ bilinguals \\
\hline & Rosseli et al. (2002) & monolinguals $=$ bilinguals \\
\hline & Taler et al. (2013) & monolinguals $=$ bilinguals \\
\hline & Vega-Mendoza et al. (2015) & monolinguals $=$ bilinguals \\
\hline & Bialystok et al. (2008a) & monolinguals $>$ bilinguals \\
\hline & Bialystok et al. (2008b; Study 2) & monolinguals $>$ bilinguals \\
\hline & Friesen et al. (2015) & monolinguals $>$ bilinguals \\
\hline & Gollan et al. (2002) & monolinguals $>$ bilinguals \\
\hline & Kormi-Nouri et al. (2012) & monolinguals $>$ bilinguals \\
\hline & Portocarrero et al. (2007) & monolinguals $>$ bilinguals \\
\hline & Rosseli et al. (2002) & monolinguals $>$ bilinguals \\
\hline & Rosseli et al. (2000) & monolinguals $>$ bilinguals \\
\hline & Sandoval et al. (2010) & monolinguals $>$ bilinguals \\
\hline
\end{tabular}

Letter fluency

Bialystok et al. (2008b; Study 2)

monolinguals $<$ bilinguals

Friesen et al. (2015)

monolinguals $<$ bilinguals

Kormi-Nouri et al. (2003)

monolinguals $<$ bilinguals

Kormi-Nouri et al. (2012)

monolinguals $<$ bilinguals

Luo et al. (2010)

monolinguals $<$ bilinguals

Bialystok et al. (2008b; Study 2)

monolinguals $=$ bilinguals

Blumenfeld et al. (2016)

Current study

monolinguals $=$ bilinguals

monolinguals $=$ bilinguals

Friesen et al. (2015)

monolinguals $=$ bilinguals

Luo et al. (2010)

monolinguals $=$ bilinguals

Portocarrero et al. (2007)

monolinguals $=$ bilinguals 


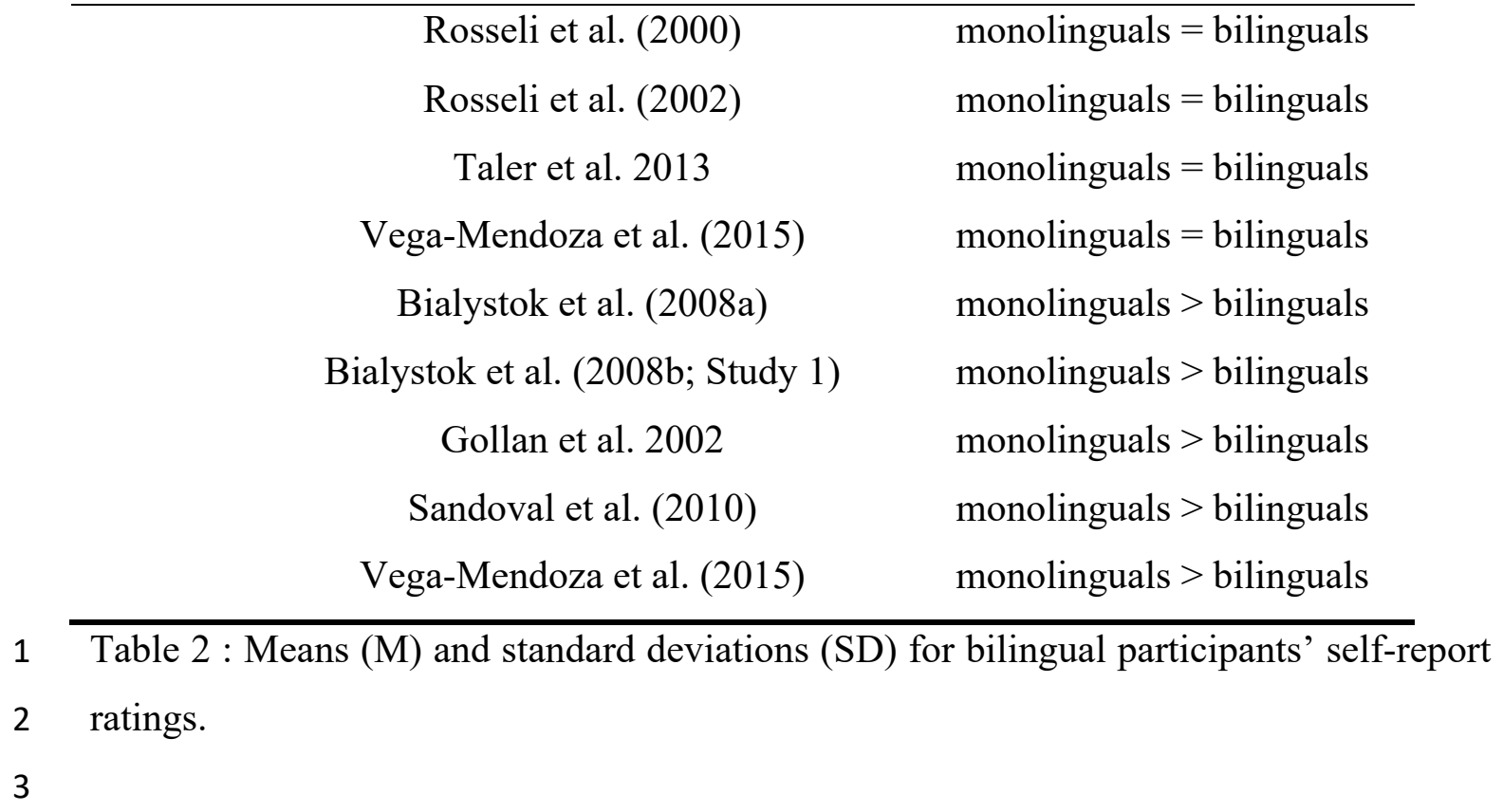

24 European Portuguese-French bilinguals

\begin{tabular}{lll} 
& $M$ & $S D$ \\
\cline { 2 - 3 } Age & 34.8 & 5.7
\end{tabular}

Percent daily use of

European Portuguese

$94.8 \quad 10.4$

Percent daily use of French

$26.7 \quad 26.0$

Years in Portugal

$\begin{array}{ll}21.7 & 4.7\end{array}$

Years in France

$12.9+3.1$

European Portuguese

$\begin{array}{lll}\text { proficiency } & 7.0 & 0.0\end{array}$

French proficiency

$6.9 \quad 0.4$

English proficiency

$3.9 \quad 1.8$

4 Note: Language use scores represent the estimated percentage of daily use on a five

5 point scale $(1 \%, 25 \%, 50 \%, 75 \%, 100 \%)$. Note that participants did not respect the

6 instructions that percentages should sum up to $100 \%$. Proficiency ratings are on a 1-7

7 scale, where 1 indicates "very poor knowledge of the language", and 7 indicates "native 
1 proficiency". Proficiency values represent the average of the participants' responses in 2 four domains (speaking, writing, reading, and listening).

3

4

5

6

7 
1 Table 3:

2 Predictors of cognate production probability in the typed fluency task (Experiment 1).

\begin{tabular}{lllcc}
\hline Predictor & $\beta$ & $S E \beta$ & $z$-value & $p$-value \\
\hline Intercept & 0.72 & 0.12 & 6.20 & $<0.001$ \\
Bilinguals vs. monolinguals & -0.11 & 0.05 & -2.39 & 0.017 \\
Letter vs. semantic task & -0.72 & 0.15 & -4.69 & $<0.001$ \\
Order & -0.01 & $<0.01$ & -5.37 & $<0.001$ \\
\hline
\end{tabular}

3 Note: $\mathrm{SE}=$ standard error. Cognate production probability was coded 0 for

4 cognates and 1 for non-cognates.

5 
1 Table 4:

2 Category and letter combinations used in the mixed task (Experiment 2).

\begin{tabular}{lll}
\hline Letter Animals & Musical Vegetables Tools Professions Vehicles \\
& Inst. &
\end{tabular}

\begin{tabular}{|c|c|c|c|c|c|c|}
\hline A & $\mathrm{X}$ & & & & $\mathrm{X}$ & \\
\hline B & $\mathrm{X}$ & $\mathrm{X}$ & & $\mathrm{x}$ & $\mathrm{x}$ & $\mathrm{X}$ \\
\hline $\mathrm{C}$ & & $x$ & & & & \\
\hline$E$ & $\mathrm{X}$ & & & & $\mathrm{X}$ & $\mathrm{X}$ \\
\hline $\mathrm{F}$ & & $\mathrm{X}$ & & & $\mathrm{x}$ & $\mathrm{X}$ \\
\hline $\mathrm{G}$ & & & & & $\mathrm{x}$ & \\
\hline I & & & & & $\mathrm{X}$ & \\
\hline $\mathrm{L}$ & & & & $\mathrm{x}$ & & $\mathrm{X}$ \\
\hline $\mathrm{M}$ & $\mathrm{X}$ & & & $\mathrm{X}$ & & \\
\hline $\mathrm{N}$ & & & & & $\mathrm{x}$ & \\
\hline$P$ & & & $\mathrm{X}$ & & & \\
\hline $\mathrm{R}$ & $x$ & & & $\mathrm{X}$ & & \\
\hline$S$ & & $\mathrm{X}$ & $\mathrm{X}$ & & & \\
\hline $\mathrm{T}$ & $X$ & $\mathrm{X}$ & $\mathrm{X}$ & & & $\mathrm{x}$ \\
\hline
\end{tabular}

3

4

5

6 Figure 1: Distribution of responses across time for monolingual and bilingual 7 participants in the typed fluency task (Experiment 1). 


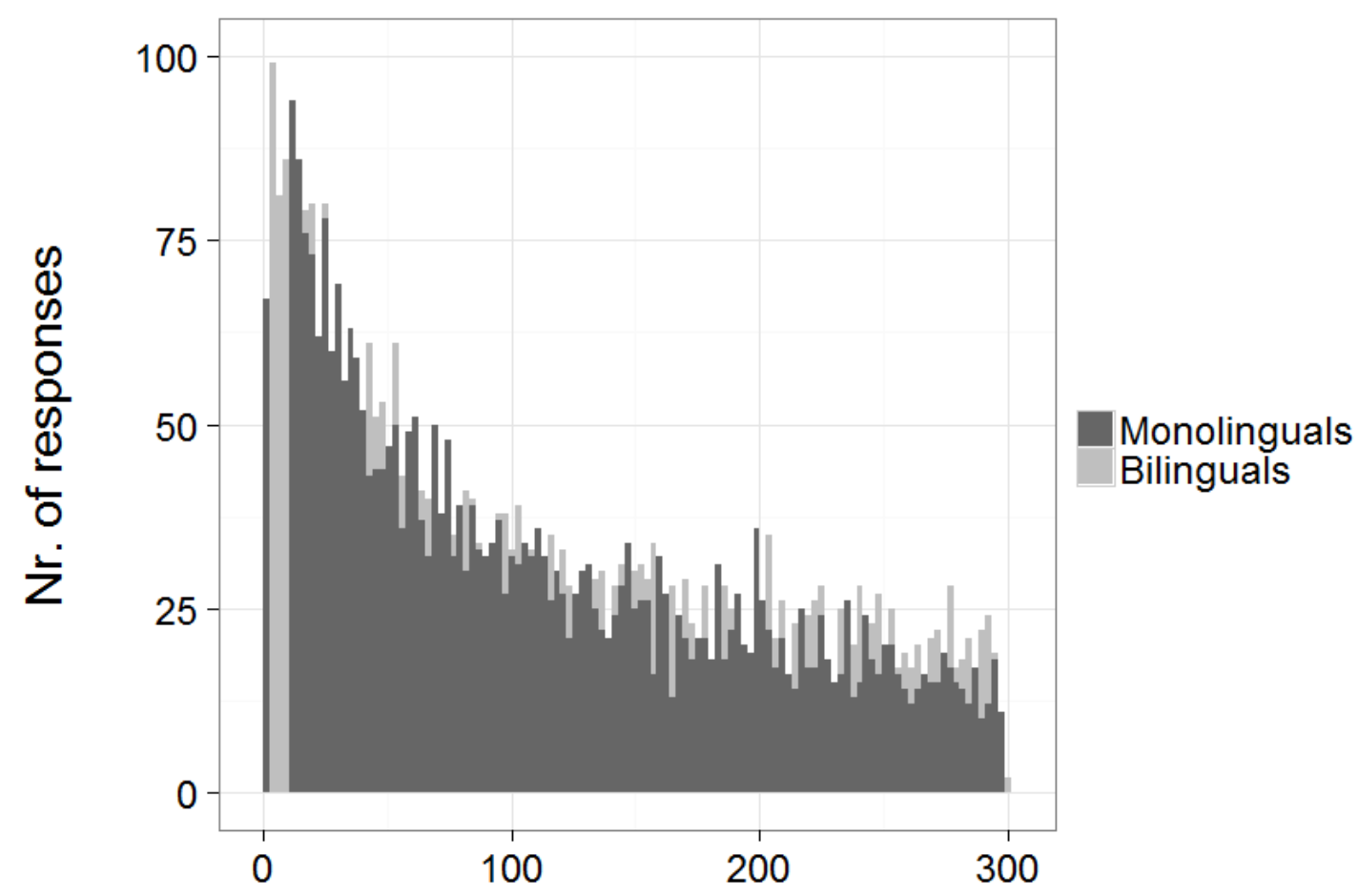

Time in seconds 
1 Figure 2: Mean percentage of cognate production for mono- and bilinguals in the

2 semantic and letter category task (Experiment 1). Error bars indicate the standard error 3 of the mean.

4

Semantics

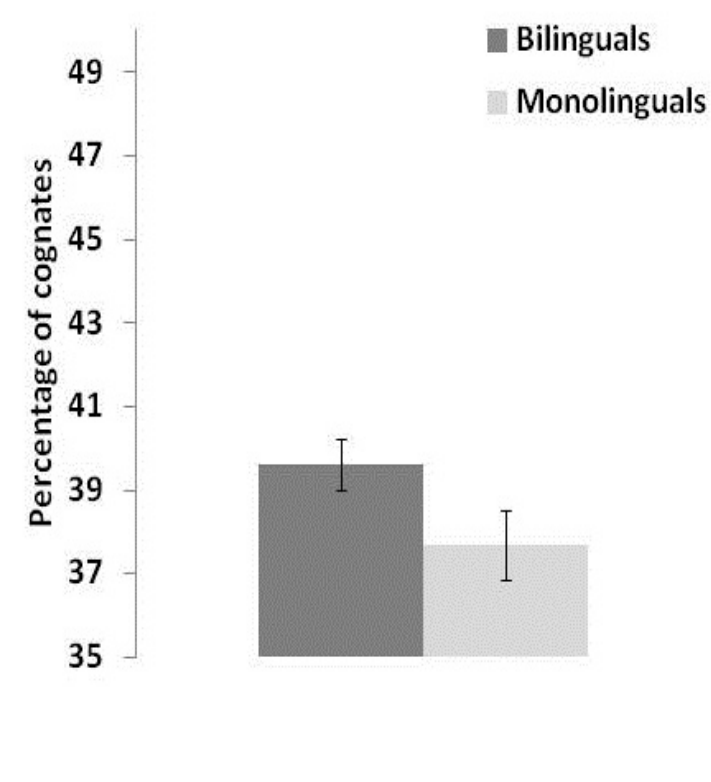

Letters

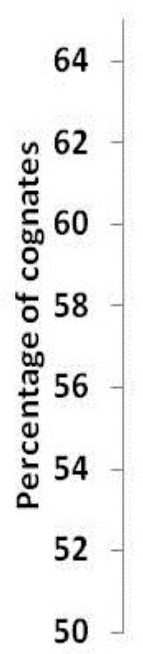

Bilinguals

Monolinguals

5 
1 Figure 3: Mean percentage of cognate production for mono- and bilinguals in the mixed

2 task (Experiment 2). Error bars indicate the standard error of the mean.

3

4

\section{Mixed}

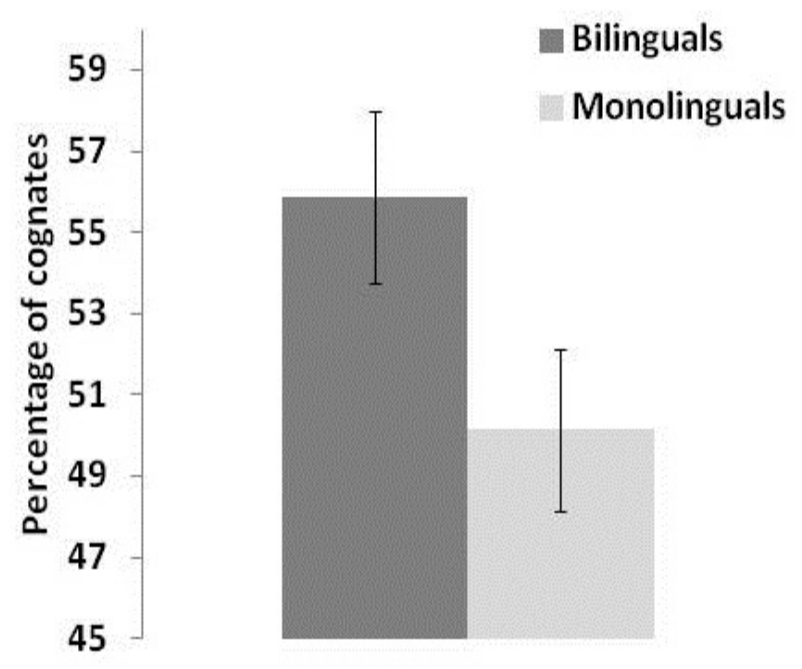

5

6

7 